\title{
Determination of Pharmacokinetic Parameters of a Four- Armed, Guanidinium-Rich Structurally Nanoengineered Antimicrobial Peptide Polymer: A Research Protocol
}

\author{
Matthew C. So, BHSc. (Honours) Student [1]*, Rohan Aananth, BHSc. (Honours) Student [1] \\ Emmanuel Z. Suntres, BHSc. (Honours) Student [1] \\ [1] Faculty of Health Sciences, McMaster University, Hamilton, ON, Canada L8S 4L9 \\ *Corresponding Author: som5@mcmaster.ca
}

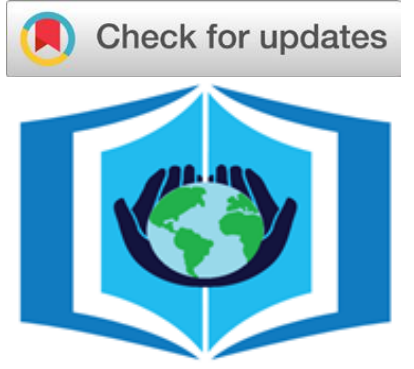

URNCST Journal

"Research in Earnest"

\begin{abstract}
Introduction: Antibacterial resistance has accentuated the need for the development of novel, efficacious pharmaceuticals. Structurally nanoengineered antimicrobial polypeptide polymers (SNAPPs) have shown promise as a candidate for a new antibacterial pharmaceutical class which may help overcome the problem of antibacterial resistance in humans or animals. Particularly, the SNAPP with a chemical formula (RGRGRGRGRGRG) $\mathrm{K}_{2} \mathrm{~K}-\mathrm{NH}_{2}$ (4R6G6) has been shown to exhibit negligible hemolysis while retaining low minimal inhibitory concentrations against bacteria. An important consideration in drug development is pharmacokinetic studies, however, there have been no prior pharmacokinetic studies involving SNAPPs. Therefore, the objective of this study is to determine the pharmacokinetic parameters of 4R6G6.

Methods: 4R6G6 will be synthesized and purified according to previously reported methods. 4R6G6 will be administered to BALB/c mice intravenously, serial blood samples will be taken from 0-48 hours after SNAPP administration and serum 4R6G6 concentrations will be quantified over time by liquid chromatography mass spectrometry. This information will be used to calculate key pharmacokinetic parameters using Pmetrics.

Results: We expect that the half-life of elimination will be on the order of hours and will exceed 3 hours, while the volume of distribution will be equal to the plasma volume of a mouse $(1.2 \mathrm{~mL} / \mathrm{mouse})$

Discussion: The half-life of elimination of 4R6G6 will influence its desirability as a future drug target. Additionally, the volume of distribution is expected to indicate a distribution into plasma, and can be used to calculate the desired dose for a certain plasma concentration in future studies.

Conclusion: Given the expected half-life of elimination on the order of hours, we expect 4R6G6 to be a strong candidate for further translational study in the race to combat antibacterial resistance. Future directions include the quantification of the safety of the drug by determining the therapeutic index in vivo.
\end{abstract}

Keywords: antibiotic resistance; antimicrobial peptide; dendrimer; drug development; LC-MS; pharmacokinetics; SNAPP

\section{Introduction}

Antibiotic Resistance

Antibiotic resistance (ABR) occurs when bacteria no longer respond to antibiotics designed to kill them [1]. ABR has resulted in a substantial burden to the healthcare system. According to the Council of Canadian Academies (CCA), 15 Canadians died each day in 2018 as a direct result of antibiotic-resistant infections [2]. Drug development by the pharmaceutical industry has historically focused on modifying existing antibiotic classes [3]. However, this paradigm has contributed to the ABR crisis as bacteria resistant to one antibiotic often develop resistance to other members of the same antibiotic class [4].

\section{Background of SNAPPs}

Structurally nanoengineered antimicrobial polypeptide polymers (SNAPPs) are a type of synthetic antimicrobial peptide (AMP) that takes a novel approach to combating bacteria [5]. Rather than inhibiting the synthesis of crucial bacterial biomolecules, many AMPs permeabilize bacterial membranes, leading to bacterial death via unregulated ion flux [6]. SNAPPs expand on the idea of AMPs by attaching many AMPs to a core, forming a dendrimer (a star-shaped macromolecule forming a nanostructure) which delivers a higher local concentration of AMPs to a bacterial cell $[5,7]$. 
UNDERGRADUATE RESEARCH IN NATURAL AND CLINICAL SCIENCE AND TECHNOLOGY (URNCST) JOURNAL Read more URNCST Journal articles and submit your own today at: https://www.urncst.com

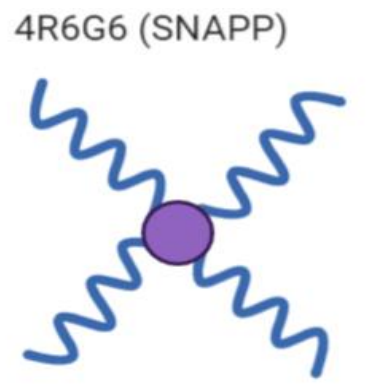

4 linear sequences, each attached to core (RGRGRGRGRGRG) ${ }_{4} \mathrm{~K}_{2} \mathrm{~K}-\mathrm{NH}_{2}$
Human a-defensin 1 (Natural AMP)

1 linear sequence

ACYCRIPACIAGERRYGTCIYQGRLWAFCC

Figure 1. Conceptual comparison of 4R6G6 (a SNAPP), and human $\alpha$-defensin 1 (a natural AMP). Created with BioRender. [5, 8]

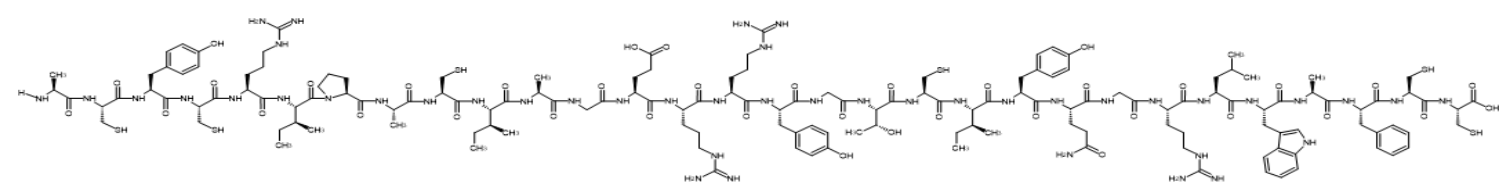

ACYCRIPACI AGERRYGTCI YQGRLWAFCC

Figure 2. Chemical structure of $\alpha$-defensin 1, a natural AMP. [8].

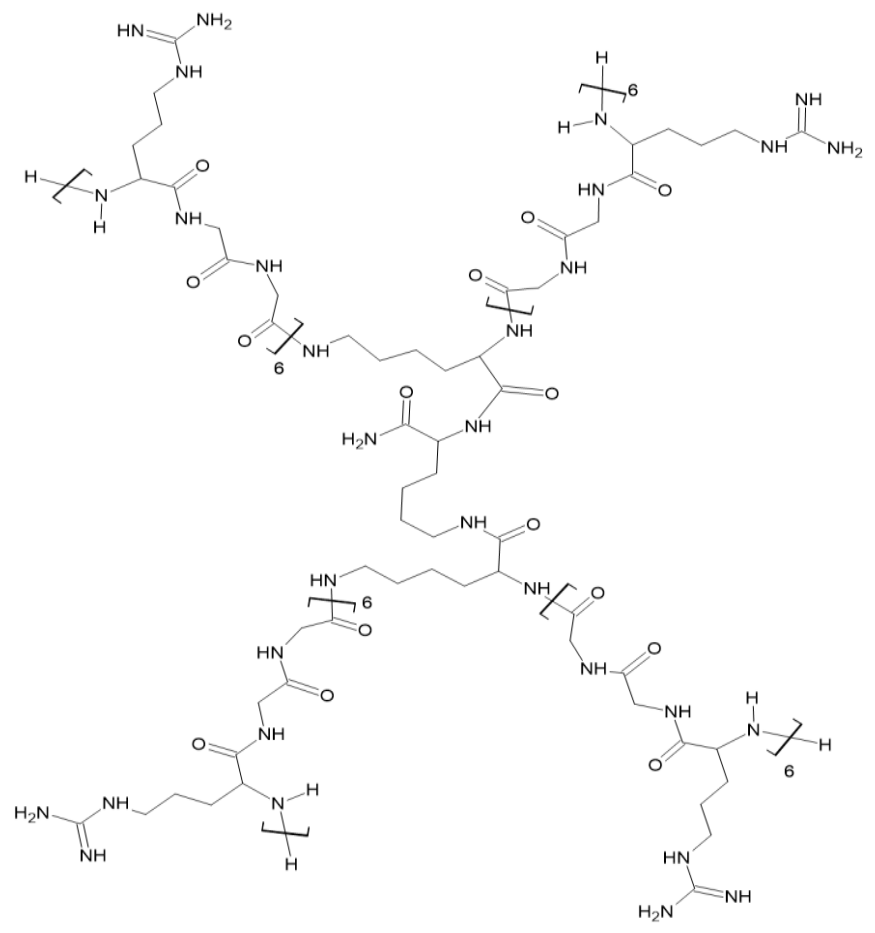

Figure 3: Chemical structure of 4R6G6, the SNAPP evaluated in this protocol [9]. 
UNDERGRADUATE RESEARCH IN NATURAL AND CLINICAL SCIENCE AND TECHNOLOGY (URNCST) JOURNAL Read more URNCST Journal articles and submit your own today at: https://www.urncst.com
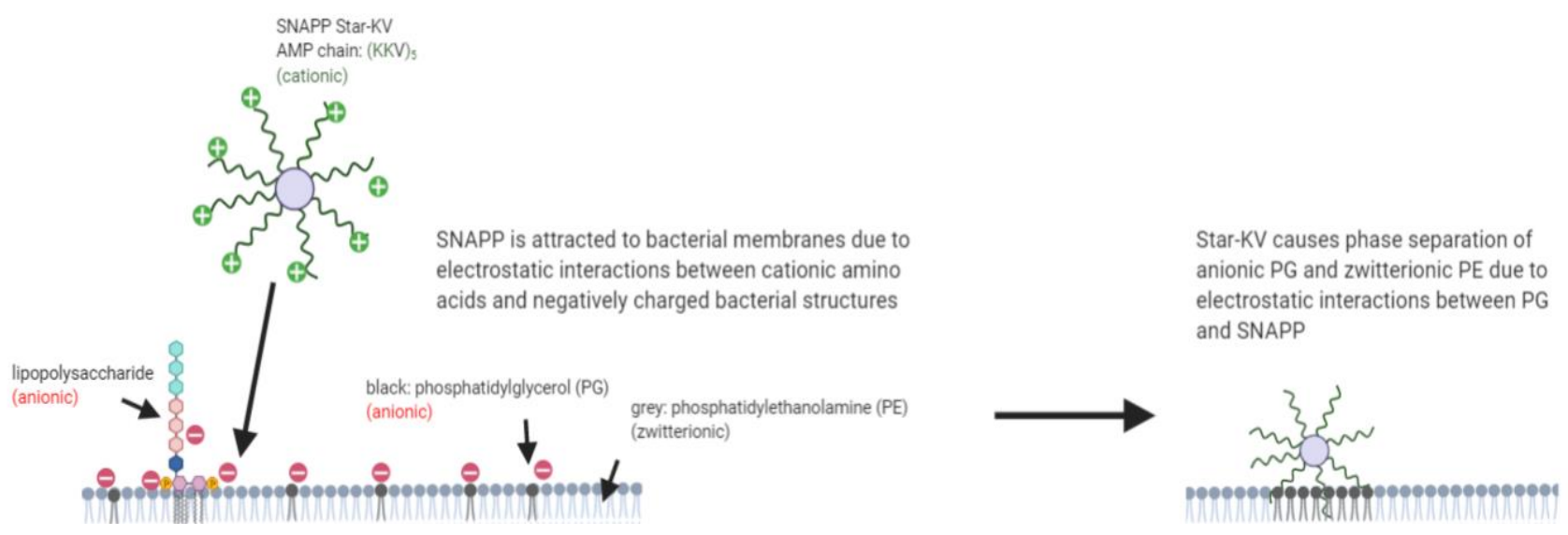

Figure 4: Electrostatic interactions between Star-KV (a SNAPP) and bacterial membranes. Created with BioRender. [10]

Mechanistic studies have shown that a Lys/Val SNAPP localizes to bacterial membranes due to electrostatic interactions between the positively charged amino acids of the SNAPP and the negatively charged structures found in bacterial membranes, including lipopolysaccharides (in Gram-negative bacteria) and anionic phospholipid heads (in all bacteria) [5]. This SNAPP-membrane interaction disrupts the bacterial membrane by inducing the separation of phospholipids in the bacterial membrane [5, 10]. An important result of this killing mechanism is that SNAPPs are likely nonspecific to bacterial strains, characterizig a broad-spectrum antibiotic [3].

Natural AMPs often cause toxicity to animals in the form of hemolysis; thus, this must be avoided in order for AMP antibiotics to have systemic applications [11, 12]. One landmark study has demonstrated that SNAPPs are effective against several strains of multi-drug resistant gram-negative bacteria ( $E$. coli, $K$. pneumoniae, $P$. aeruginosa and $A$. baumannii) with no resistance observed through multiple bacterial generations [5]. This same study also validated the safety of SNAPPs by demonstrating that SNAPPs cause insignificant hemolysis in a sheep model in vitro.

\section{$\underline{\text { Literature Search }}$}

A brief, non-exhaustive literature search was conducted by searching for the terms "structurally nanoengineered antimicrobial peptide polymer" and "star shaped antimicrobial peptide" on Google Scholar and PubMed. Many of the relevant articles in the literature discussed the synthesis of a variety of SNAPP and evaluated the antibacterial efficacy of that SNAPP in vitro [5, 9, 13, 14]. Additionally, most of these articles evaluated the toxicity of their SNAPP in vivo, and found that the SNAPP of interest was well-tolerated [5, 9, 13, 14]. No studies were found which evaluated the pharmacokinetics of a SNAPP. $\underline{\text { Rationale }}$

Briefly, pharmacokinetics is the study of the movement of exogenous compounds within the body [15]. Pharmacokinetic studies seek to determine the rates at which a drug is absorbed, distributed, metabolized, or excreted by the body. Pharmacokinetic studies therefore represent an important step in drug development, as drugs which may initially appear efficacious in vitro may fail in vivo due to poor pharmacokinetic properties. It is for this reason that we have decided to perform a pharmacokinetic study on a SNAPP.

\section{Choice of SNAPP}

Current literature has focused on optimizing the structure of SNAPPs to increase the killing efficacy against bacteria and/or decreasing toxicity towards mammalian cells, ultimately optimizing their selectivity. Therefore, we will choose a SNAPP which has demonstrated a high selectivity for the purposes of this protocol, as such a SNAPP would have the greatest clinical utility. A recent study by Wang et al. (2020) has reported a 4-armed, guanidinium-rich SNAPP with a low minimal inhibitory concentration (MIC) against both Gram-positive and Gramnegative bacteria, while exhibiting exceptionally low hemolysis against rat red blood cells in vitro [9]. The reported selectivity of this guanidinium-rich SNAPP is significantly higher than the reported selectivities of a different class of SNAPPs consisting of poly(L-lysine) chains grafted to a branched polyethylenimine core (PEI- $g$ PLL) [13]. An additional advantage of 4-armed SNAPPs such as the ones reported by Wang et al. (2020) is that they are easier to produce than SNAPPs with a greater number of arms [14]. Thus, we will choose to evaluate the pharmacokinetic parameters of the SNAPP with a chemical formula of (RGRGRGRGRGRG) ${ }_{4} \mathrm{~K}_{2} \mathrm{~K}-\mathrm{NH}_{2}$ (4R6G6) [9]. The chemical structure of 4R6G6 may be found in Figure 2. 


\section{Methods}

SNAPP Synthesis

4R6G6 will be synthesized using methods described by Wang et al. (2020) [9]. Conceptually, the 'core' of the structure, containing four primary amines, will be created by coupling lysine to a resin, then coupling two more lysine molecules to the two free amine termini of the resin-bound lysine. Then, the 'arms' of the structure will be created using sequential additions of glycine and arginine. The completed dendrimer will be then cleaved from the resin and purified using high-performance liquid chromatography (HPLC) following the conditions described below. Electrospray ionization mass spectrometry (ESI-MS), and H-NMR will be used to confirm the successful synthesis of 4R6G6. Following confirmation, the 4R6G6 solution will be lyophilized to yield a solid.

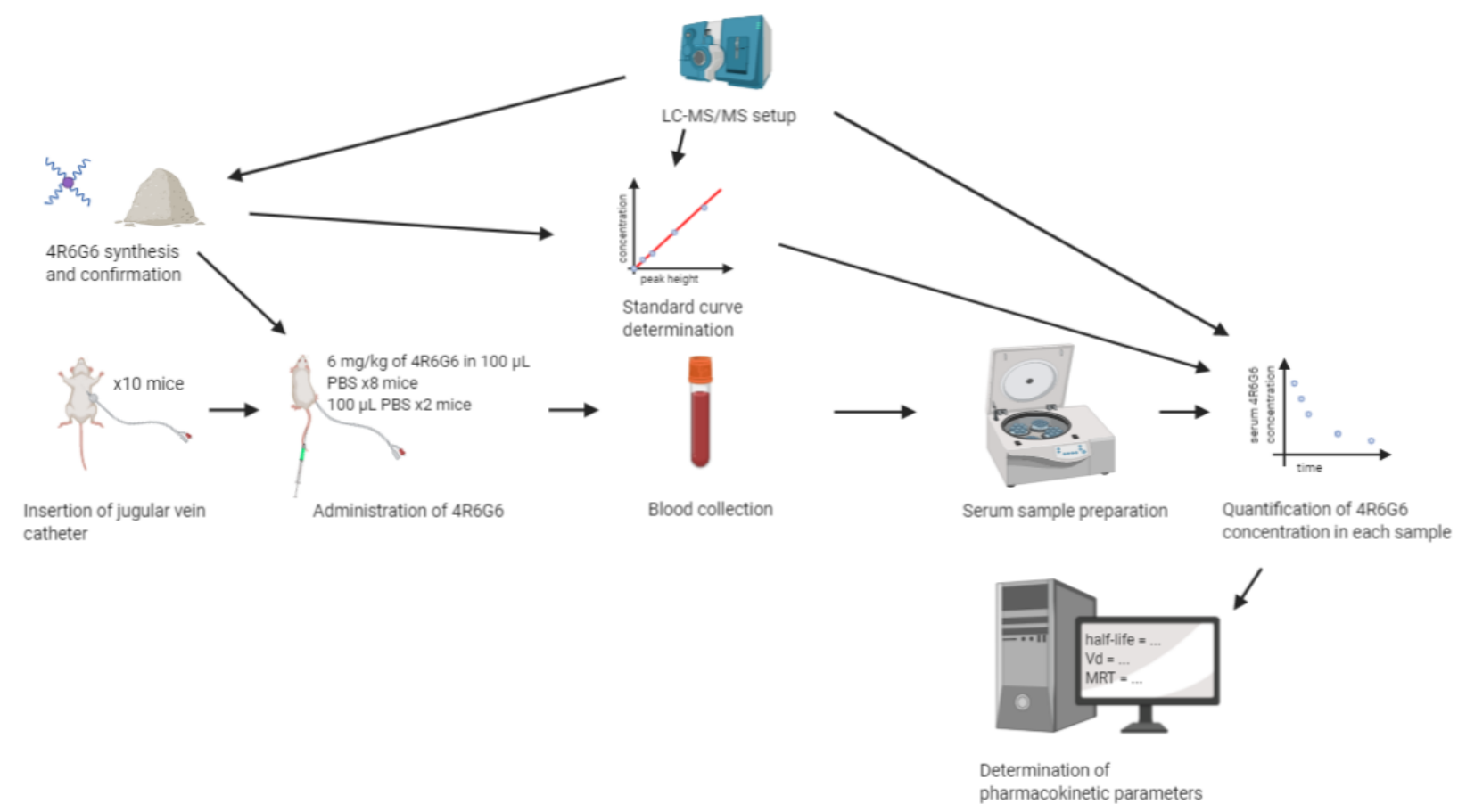

Figure 5: Schematic of experimental protocol. An arrow originating from one step and pointing to another indicates that the completion of the latter step is dependent on the former step.

Conditions for Mass Spectrometry

To determine a suitable ion transition to monitor, ESIMS will be performed on a SNAPP solution produced by mixing 4R6G6 with $0.1 \%$ trifluoroacetic acid (TFA) in water to a final concentration of $10 \mathrm{mg} / \mathrm{mL}[5,9,16]$. Suitable transitions will produce ions which appear as local maxima on product ion plots. A triple quadrupole mass spectrometer will be operated in multiple reaction monitoring mode with a positive ion electrospray source [16]. The initial MS parameters will be as follows: capillary voltage set as $4.5 \mathrm{kV}$, collision energy set as $35.0 \mathrm{~V}$, collision cell exit potential set as $10.0 \mathrm{~V}$, which are within the range of parameters used by Chen et al. (2018). These parameters may be further optimized by modifying the parameters with a goal of obtaining transitions with the largest signal-to-noise ratio on the product ion plot produced by a mass spectrometer, resulting in a more precise estimate of SNAPP concentration. According to the ESI-MS spectra published by Wang et al. (2020), the 4R6G6 mass spectra is expected to have strong peaks resulting in the formation of ions at $691.00,614.35$, and $789.50 \mathrm{M} / \mathrm{Z}$ [9].

\section{Conditions for LC-MS}

To quantify peptide concentration, liquid chromatography mass spectrometry (LC-MS) will be used [17]. 4R6G6 concentrations will be measured by LC-MS, consisting of a HPLC system coupled to a triple quadrupole mass spectrometer [9]. The mobile phases will consist of $0.1 \%$ TFA in water (mobile phase A) and $0.1 \%$ TFA in acetonitrile (mobile phase B). Peptides will be bound to a HPLC column at $40^{\circ} \mathrm{C}$ for 0.5 minutes with $100 \%$ mobile phase A, then eluted with a linear gradient of 5 to $100 \%$ mobile phase $\mathrm{B}$ for 40 minutes at a $1 \mathrm{~mL} / \mathrm{min}$ flow rate. Peptide solutions eluted to mobile phase B will be processed with MS. To purify the synthesized SNAPPs, a $16 \mathrm{~mL} / \mathrm{min}$ flow rate will be used following the above parameters. 
UNDERGRADUATE RESEARCH IN NATURAL AND CLINICAL SCIENCE AND TECHNOLOGY (URNCST) JOURNAL Read more URNCST Journal articles and submit your own today at: https://www.urncst.com

\section{Determination of a Standard Curve}

The desired upper limit of quantification is $200 \mu \mathrm{g} / \mathrm{mL}$, which is two times greater than the maximum possible concentration of 4R6G6 at the time of the first blood collection at 2.5 minutes (assuming that the 4R6G6 will be sufficiently distributed in the bloodstream by this point) $[9$, 18]. 6 standard solutions of concentrations $6.3,12.5,25$, 50,100 , and $200 \mu \mathrm{g} / \mathrm{mL}$ will be produced by mixing 4R6G6 with $0.1 \%$ TFA in water. MS will be performed on each standard solution. A standard curve will be created through linear regression of the known 4R6G6 concentration against the peak height for the ion transition determined previously. The limit of detection (LOD) will be computed as $3 \mathrm{SD} / \mathrm{b}$, where SD represents the standard deviation of the $y$ intercept of the regression line, and $\mathrm{b}$ represents the slope of the calibration curve [19].

\section{Administration and Delivery}

10 wild-type $\mathrm{BALB} / \mathrm{c}$ mice, maintained under pathogen-free conditions will be used at 8 to 10 weeks of age. $6 \mathrm{mg} / \mathrm{kg}$ of $4 \mathrm{R} 6 \mathrm{G} 6$ in $100 \mu \mathrm{L}$ of phosphate-buffered saline will be administered via intravenous injection to the lateral tail veins of a group of 8 mice $[9,13,14]$. The lateral tail vein injection will be done using a 27-30 gauge needle towards the direction of the head, as established in a protocol by the American Association for Laboratory Animal Science [20]. As a vehicle control, $100 \mu \mathrm{L}$ of phosphate-buffered saline will be administered intravenously to 2 mice in the same manner [14].

\section{Blood Collection}

Similarly to Lei et al. (2018), blood samples will be collected at 2.5, 5, 10, 20, 30 minutes, 1, 2, 4, 8, 12, 24, 36, and 48 hours, after initial administration of the SNAPP formulation [21]. However, as this is a repeated blood collection, blood will be collected from the jugular vein through the implantation of a catheter according to the protocol published by Park et al. (2018) [22]. Briefly, mice will be anesthetized through the administration of an inhalation agent. Hair near the area of catheterization will be removed, and the location of the right external jugular vein will be identified. Incisions will be made to expose the vein, a suture will be slid underneath, then tied around the vein. A catheter will be implanted by making a small incision in the wall of the vein, then sliding the tip into the vein. Blood samples will be taken by connecting a line of tubing to the implanted catheter.

\section{Preparation of Serum Samples}

Blood serum sample preparation will be performed according to a protocol previously established by Lei $e t$ al. (2018) [21]. Blood samples will be centrifuged at 3,000 rpm for 10 minutes to obtain serum samples. $0.5 \mathrm{~mL}$ of $5 \%$ acetic acid in acetonitrile will be added to $200 \mu \mathrm{L}$ of the serum. This mixture will be vortexed for 2 minutes, then centrifuged at $12,000 \mathrm{rpm}$ for $10 \mathrm{~min}$. The aqueous phase will be removed and dried under nitrogen in a water bath at $50^{\circ} \mathrm{C}$. $200 \mu \mathrm{L}$ of $0.1 \%$ TFA in water (mobile phase A) will be used to dissolve the resulting sample. The final samples will be filtered through membrane filters with a $0.22 \mu \mathrm{m}$ pore size, and analyzed with LC-MS using the protocol described above. Serum SNAPP concentrations will be quantified by inputting the peak height into the formula of the standard curve.

\section{Pharmacokinetic Analysis}

The pharmacokinetic parameters area under the curve (AUC), mean retention time (MRT), body clearance (CL), volume of distribution $\left(\mathrm{V}_{\mathrm{d}}\right)$, and half life of elimination $\left(\mathrm{T}_{\text {half }}\right)$ will be obtained using the makeNCA command from the Pmetrics package in $\mathrm{R}$ [23]. The pharmacokinetic parameter $\mathrm{K}_{\mathrm{e}}$ will be calculated as $\ln (2) / \mathrm{T}_{\text {half }}$.

\section{Results}

It is expected that the SNAPP synthesis will produce the expected product with a high degree of purity, as this synthesis procedure was used by Wang et al. (2020) to obtain a product with $96.3 \%$ purity [9]. It is expected that the mass spectrometry with the aforementioned parameters will result in product ion transitions with the formation of ions at $691.00,614.35$, and $789.50 \mathrm{M} / \mathrm{Z}$ [9]. The correlation coefficient for the LC-MS standard curve should be close to 1 to ensure precision of the results [24]. Based on the in vitro degradation study of a different SNAPP (PEI- $g$-PLL) conducted by Lu et al. (2019), $\mathrm{T}_{\text {half }}$ is expected to be on the order of hours, and is expected to exceed 3 hours but is not expected to exceed 24 hours [13]. $\mathrm{V}_{\mathrm{d}}$ is expected to be approximately equal to the plasma volume in rats (1.2 $\mathrm{mL} /$ mouse). The control mice are expected to have a 4R6G6 level below the LOD in the blood, as 4R6G6 should not be present in the controls.

\section{Discussion \\ Design Choices}

The protocol described will allow for the determination of pharmacokinetic properties of SNAPPs administered intravenously in a murine model. The SNAPP synthesis procedure used by Wang et al. (2020) was the preferred method of producing 4R6G6, as it had been previously shown to produce 4R6G6 of high purity [9]. LC-MS was chosen as a method of determining the serum 4R6G6 concentration as it had previously been used to accurately and precisely determine the serum concentration of a different AMP [16]. The concentrations of the standards for the standard curve were chosen such that the standard curve could be shown to be linear across several orders of magnitude of concentration. BALB/c mice, the most widely used inbred strains in animal experimentation, were selected as the model organism as they are commonly used to test drugs which are not yet known to be safe in humans $[25,26]$. We chose to evaluate the pharmacokinetics of intravenously administered 4R6G6, as intravenously 
UNDERGRADUATE RESEARCH IN NATURAL AND CLINICAL SCIENCE AND TECHNOLOGY (URNCST) JOURNAL Read more URNCST Journal articles and submit your own today at: https://www.urncst.com

administered AMPs are generally preferred because of their longer elimination half-life (ranging from hours to days) compared to AMPs administered through other routes [27]. The dose of $6 \mathrm{mg} / \mathrm{kg}$ for the experimental group was selected as it has been previously found to be a safe and effective dose for 4R6G6 by Wang et al. (2020) [9]. The catheterization procedure is required as it is one of the few methods able to withdraw serial blood samples within a relatively short period of time without harming the mice [28]. The time points for blood collection were selected to be similar to the time points used in a similar study by Lei et al. (2018) researching the pharmacokinetics of Piscidin1, another AMP with a half-life on the order of hours [21]. There is a shorter duration between blood collections immediately after administration, as it is expected that the blood concentration of SNAPPs would change the most during this time.

\section{Significance}

$\mathrm{V}_{\mathrm{d}}$ is a pharmacokinetic parameter representing the apparent volume in which the drug resides in the body [29]. If the measured $\mathrm{V}_{\mathrm{d}}$ is similar to the volume of plasma in mice $(1.2 \mathrm{~mL} / \mathrm{mouse})$ as expected, this would confirm that the drug is distributed in the bloodstream [13]. Clinically, the $\mathrm{V}_{\mathrm{d}}$ may be used to determine the appropriate intravenous drug dosage based on a desired drug concentration with the formula dose $=C_{p} V_{d}$, where $\mathrm{C}_{p}$ represents the desired plasma drug concentration [30]. The measured AUC may be used in future studies as part of the measurement of bioavailability when examining another form of administration as calculated by the following equation: bioavailability $=\mathrm{AUC}_{\text {other }} / \mathrm{AUC}_{\mathrm{IV}}$ [31] .

$\mathrm{T}_{\text {half }}$ is another important pharmacokinetic parameter to optimize. It is generally accepted that elimination of drugs follows first-order exponential decay [15]. $\mathrm{T}_{\text {half }}$ therefore represents the time it takes for $50 \%$ of a drug to be removed from the body. A $\mathrm{T}_{\text {half }}$ which is too long may result in complications due to the accumulation of drug in the system, whereas a $T_{\text {half }}$ which is too short may necessitate frequent dosing to obtain a desired steady-state concentration [32]. It has been suggested that a dosing interval for intravenous administration can be approximately once per half life (for example, once per day for a drug with a half-life of 24 hours) [33]. It is expected that $\mathrm{T}_{\text {half }}$ should be greater than 3 hours, as it was previously shown that a PEI-g-PLL SNAPP was degraded by less than half after 3 hours of incubation with the protease trypsin (which likely represents much faster degradation than would occur in the body) [13]. It is also expected that $\mathrm{T}_{\text {half }}$ should be less than 24 hours, as the PEI$g$-PLL SNAPP was completely degraded after 24 hours under the same conditions.

\section{Limitations}

There exist numerous possible variations on this research which will not be explored in this proposal.
Several different types of SNAPPs exist, which may vary in their pharmacokinetic properties. Different methods of administration and the use of different vehicles of administration may also differ in their observed pharmacokinetic properties [34]. Additionally, the mechanism of the metabolism of SNAPPs has not yet been explored, although we hypothesize that SNAPPs might be metabolized similarly to other AMPs.

\section{Conclusions}

Given the absence of literature on the pharmacokinetic properties of SNAPPs, this study outlines a protocol that can be used to determine the pharmacokinetic parameters of the SNAPP 4R6G6 administered intravenously. We propose preparing and administering 4R6G6, then determining the pharmacokinetic parameters by observing the serum SNAPP concentration over time with LC-MS. It is hypothesized that these parameters will be on the order of hours, which will provide an indication that SNAPPs may be suitable drug candidates. This study has the potential to advance the development of a new drug which may combat ABR. This design involving a murine model allows for fast, preliminary study results. However, future translational studies will be needed to confirm the pharmacokinetics of 4R6G6 in humans or other animals.

SNAPPs are a promising target for combating future antibiotic resistance. However, further research is required in order to achieve the goal of determining the viability of SNAPPs as a drug class. In this protocol, we propose an important initial step, the determination of pharmacokinetic parameters in a mouse model. However, there is still much work to be done to achieve this goal. For example, one other important step is the determination of the safety of the drug in vivo, by measuring its therapeutic index. Several other studies have evaluated the safety of SNAPPs, for example, by performing hemolysis assays as quantitative toxicology measures [9, 13]. However, none have computed a therapeutic index by the ratio of the median lethal dose and median effective dose method in vivo [35].

\section{List of Abbreviations Used}

4R6G6: The peptide with the formula (RGRGRGRGRGRG) ${ }_{4} \mathrm{~K}_{2} \mathrm{~K}-\mathrm{NH}_{2}$

ABR: antibiotic resistance

AMP: antimicrobial peptide

AUC: area under curve

CCA: Council of Canadian Academies

CL: alearance

ESI-MS: electrospray ionization mass spectrometry

H-NMR: proton nuclear magnetic resonance

HPLC: high performance liquid chromatography

$\mathrm{K}_{\mathrm{e}}$ : elimination rate constant

LC-MS: liquid chromatography mass spectrometry

$\mathrm{M} / \mathrm{Z}$ : mass to charge ratio

MIC: minimal inhibitory concentration

MRT: mean retention time 
UNDERGRADUATE RESEARCH IN NATURAL AND CLINICAL SCIENCE AND TECHNOLOGY (URNCST) JOURNAL Read more URNCST Journal articles and submit your own today at: https://www.urncst.com

MS: mass spectrometry

PEI-g-PLL: poly(L-lysine) grafted to branched

polyethylenamine

rpm: rotations per minute

SNAPP: structurally nanoengineered antimicrobial polypeptide polymer

TFA: trifluoroacetic acid

$\mathrm{T}_{\text {half: }}$ half life of elimination

$\mathrm{V}_{\mathrm{d}}$ : volume of distribution

\section{Conflicts of Interest}

The authors declare that they have no conflicts of interest.

\section{Ethics Approval and/or Participant Consent}

As this is a research protocol which has yet to be conducted, it did not require ethics approval and/or patient consent.

\section{Authors' Contributions}

MS: Significantly contributed to study design, drafting and revising the manuscript, and gave final approval of the work to be published.

RA: Significantly contributed to study design, drafting and revising the manuscript, and gave final approval of the work to be published.

ES: Significantly contributed to drafting and revising the manuscript, and gave final approval of the work to be published.

\section{Acknowledgements}

All chemical structure figures created with ChemSketch (ACD/Labs). All non-chemical structure figures created with BioRender.com.

\section{Funding}

This study was not funded.

\section{References}

[1] Antibiotic Resistance Questions and Answers [Internet]. Centers for Disease Control and Prevention. [cited 2020 May 25]. Available from: https://www.cdc. gov/antibiotic-use/community/about/antibioticresistance-faqs.html

[2] Dall C. Drug resistance threatens Canada's health, economy, report says [Internet]. CIDRAP. [cited 2020 May 25]. Available from: https://www.cidrap.umn.edu/ news-perspective/2019/11/drug-resistance-threatenscanadas-health-economy-report-says

[3] Fair RJ, Tor Y. Antibiotics and Bacterial Resistance in the 21st Century. Perspectives in Medicinal Chemistry. 2014 Aug 28;6. https://doi.org/10.4137/PMC.S14459

[4] Aslam B, Wang W, Arshad MI, Khurshid M, Muzammil S, Rasool MH, et al. Antibiotic resistance: a rundown of a global crisis. Infection and Drug Resistance. 2010 Oct 10;Volume 11:1645-58. https://doi.org/10.2147/IDR.S173867

[5] Lam SJ, O'brien-Simpson NM, Pantarat N, Sulistio A, Wong EHH, Chen Y-Y, et al. Combating multidrug- resistant Gram-negative bacteria with structurally nanoengineered antimicrobial peptide polymers. Nature Microbiology. 2016 Sep 12;1(11). https://doi.org/10.1038/nmicrobiol.2016.162

[6] Kumar P, Kizhakkedathu J, Straus S. Antimicrobial Peptides: Diversity, Mechanism of Action and Strategies to Improve the Activity and Biocompatibility In Vivo. Biomolecules. 2018 Mar 19;8(1):4. https://doi.org/10.3390/biom8010004

[7] Abbasi E, Aval S, Akbarzadeh A, Milani M, Nasrabadi $\mathrm{H}$, Joo S, et al. Dendrimers: synthesis, applications, and properties. Nanoscale Research Letters. 2014 May 21;2014;9(1):247. https://doi.org/10.1186/1556-276X9-247

[8] Berman HM. The Protein Data Bank. Nucleic Acids Research. 2000 Jan 1;28(1):235-42. https://doi.org/ 10.1093/nar/28.1.235

[9] Wang J, Lu C, Shi Y, Feng X, Wu B, Zhou G et al. Structural Superiority of Guanidinium-Rich, FourArmed Copolypeptides: Role of Multiple PeptideMembrane Interactions in Enhancing Bacterial Membrane Perturbation and Permeability. ACS Applied Materials \& Interfaces. 2020 Apr 3;12(16): 18363-18374. https://doi.org/10.1021/acsami.0c02752

[10]Zhang Y, Chen T, Pan Z, Sun X, Yin X, He M, et al. Theoretical Insights into the Interactions between StarShaped Antimicrobial Polypeptides and Bacterial Membranes. Langmuir. 2018 Oct 15;34(44):13438-48. https://doi.org/10.1021/acs.langmuir.8b02677

[11] Oddo A, Hansen PR. Hemolytic Activity of Antimicrobial Peptides. Methods in Molecular Biology Antimicrobial Peptides. 2016 Dec 31:427-35. https://doi.org/10.1007/978-1-4939-6737-7_31

[12] Liu W-P, Chen Y-H, Ming X, Kong Y. Design and Synthesis of a Novel Cationic Peptide with Potent and Broad-Spectrum Antimicrobial Activity. BioMed Research International. 2015 Nov 25;2015:1-6. https://doi.org/10.1155/2015/578764

[13] Lu C, Quan G, Su M, Nimmagadda A, Chen W, Pan M et al. Molecular Architecture and Charging Effects Enhance the In Vitro and In Vivo Performance of Multi- Arm Antimicrobial Agents Based on StarShaped Poly(1- lysine). Advanced Therapeutics. 2019 Oct 7;2(12):1900147. https://doi.org/10.1002/adtp. 201900147

[14] Shirbin SJ, Insua I, Holden JA, Lenzo JC, Reynolds EC, O'brien-Simpson NM, et al. Architectural Effects of Star-Shaped "Structurally Nanoengineered Antimicrobial Peptide Polymers" (SNAPPs) on Their Biological Activity. Advanced Healthcare Materials. 2018 Sep 2;7(21):1800627. https://doi.org/10.1002/ adhm.201800627

[15] Fan J, Lannoy IAD. Pharmacokinetics. Biochemical Pharmacology. 2014 Jan 1;87(1):93-120. https://doi.org/10.1016/j.bcp.2013.09.007 
UNDERGRADUATE RESEARCH IN NATURAL AND CLINICAL SCIENCE AND TECHNOLOGY (URNCST) JOURNAL

Read more URNCST Journal articles and submit your own today at: https://www.urncst.com

[16]Chen W, Hwang YY, Gleaton JW, Titus JK, Hamlin NJ. Optimization of a peptide extraction and LC-MS protocol for quantitative analysis of antimicrobial peptides. Future Science OA. 2018 Oct 17;5(1). https://doi.org/10.4155/fsoa-2018-0073

[17] Karpievitch YV, Polpitiya AD, Anderson GA, Smith RD, Dabney AR. Liquid chromatography mass spectrometry-based proteomics: Biological and technological aspects. The Annals of Applied Statistics. 2010;4(4):1797-823. https://doi.org/10.1214/ 10-AOAS341

[18] Fu Y, Li W, Flarakos J. Recommendations and best practices for calibration curves in quantitative LC-MS bioanalysis. Bioanalysis. 2019 Sep 6;11(15):1375-7. https://doi.org/10.4155/bio-2019-0149

[19] Stone D, Ellis J. Limits of Detection [Internet]. sites.chem.utoronto.ca. [cited 26 May 2020]. Available from:

https://sites.chem.utoronto.ca/chemistry/coursenotes/ analsci/stats/LimDetect.html

[20] Lee G, Goosens KA. Sampling Blood from the Lateral Tail Vein of the Rat. Journal of Visualized Experiments. 2015 May 18;(99). https://doi.org/ $10.3791 / 52766$

[21] Lei Z, Liu Q, Zhu Q, Yang B, Khaliq H, Sun A et al. Comparative Pharmacokinetics and Preliminary Pharmacodynamics Evaluation of Piscidin 1 Against PRV and PEDV in Rats. Frontiers in Chemistry. 2018 June 25;6. https://doi.org/10.3389/fchem.2018.00244

[22] Park AY, Plotsky PM, Pham TD, Pacak K, Wynne BM, Wall SM, et al. Blood collection in unstressed, conscious, and freely moving mice through implantation of catheters in the jugular vein: a new simplified protocol. Physiological Reports. 2018 Nov 13;6(21):e13904. https://doi.org/10.14814/phy2.13904

[23] Neely MN, Guilder MGV, Yamada WM, Schumitzky A, Jelliffe RW. Accurate Detection of Outliers and Subpopulations With Pmetrics, a Nonparametric and Parametric Pharmacometric Modeling and Simulation Package for R. Therapeutic Drug Monitoring. 2012;34(4):467-76. 2012 Nov 13;34(4):467-476. https://doi.org/10.1097/FTD.0b013e31825c4ba6

[24] Sargent M. Guide to achieving reliable quantitative LC-MS measurements. 1st ed. [Internet]. RSC Analytical Methods Committee; 2013. [cited 202022 May]. Available from: https://www.rsc.org/images/ AMC\%20LCMS\%20Guide tcm18-240030.pdf

[25]Zuberi A, Lutz C. Mouse Models for Drug Discovery. Can New Tools and Technology Improve Translational Power? ILAR Journal. 2016 Dec 5;57(2):178-185. https://doi.org/10.1093/ilar/ilw021
[26] Krupke DM, Begley DA, Sundberg JP, Richardson JE, Neuhauser SB, Bult CJ. The Mouse Tumor Biology Database: A Comprehensive Resource for Mouse Models of Human Cancer. Cancer Research. 2017 Nov 1;77(21):e67-e70. https://doi.org/10.1158/0008-5472. CAN-17-0584

[27] Tobudic S, Matzneller P, Stoiser B, Wenisch JM, Zeitlinger M, Vychytil A, et al. Pharmacokinetics of Intraperitoneal and Intravenous Fosfomycin in Automated Peritoneal Dialysis Patients without Peritonitis. Antimicrobial Agents and Chemotherapy. 2012 May 7;56(7):3992-5.ras. https://doi.org/10.1128/ AAC.00126-12

[28] Pauraman S, Raveendran R, Kesavan R. Blood sample collection in small laboratory animals. Journal of Pharmacology and Pharmacotherapeutics. 2010 Nov 10;1(2):87. https://doi.org/10.4103/0976-500X.72350

[29] Smith DA, Beaumont K, Maurer TS, Di L. Volume of Distribution in Drug Design. Journal of Medicinal Chemistry. 2015 Mar 23;58(15):5691-8. https://doi.org/ 10.1021/acs.jmedchem.5b00201

[30] Mansoor A, Mahabadi N. Volume of Distribution [Internet]. Treasure Island: StatPearls Publishing. [cited 202022 May]. Available from: https://www.ncbi.nlm.nih.gov/books/NBK545280/

[31] Jiang W, Yang J-J, Cao L, Xiao X, Shi X-L, Cao Y-X. Modifications of the Method for Calculating Absolute Drug Bioavailability. Journal of Pharmacy \& Pharmaceutical Sciences. 2016 May 26;19(2):181. https://doi.org/10.18433/J3RG78

[32] Smith DA, Beaumont K, Maurer TS, Di L. Relevance of Half-Life in Drug Design. Journal of Medicinal Chemistry. $2017 \quad$ Nov 7;61(10):4273-4282. https://doi.org/10.1021/acs.jmedchem.7b00969

[33] Birkett D. Pharmacokinetics made easy 11 Designing dose regimens. Australian Prescriber. 1996 Jul 1;19(3):76-8. $\quad$ https://doi.org/10.18773/austprescr.1996 .069

[34] Castel-Branco MM, Figueiredo IV, Falcao AC, Macedo TRA, Caramona MM. Influence of administration vehicles and drug formulations on the pharmacokinetic profile of lamotrigine in rats. Fundamental and Clinical Pharmacology. 2002 Sept 30;16(5):331-336. https://doi.org/10.1046/j.14728206.2002.00096.x

[35] Abughazaleh R, Tracy T. Therapeutic Index. Wiley StatsRef: Statistics Reference Online. 2007 Dec 14; https://doi.org/10.1002/9781118445112.stat07121 
UNDERGRADUATE RESEARCH IN NATURAL AND CLINICAL SCIENCE AND TECHNOLOGY (URNCST) JOURNAL

Read more URNCST Journal articles and submit your own today at: https://www.urncst.com

\section{Article Information}

Managing Editor: Jeremy Y. Ng

Peer Reviewers: Sonya Kouthouridis, Janice Tai

Article Dates: Received May 29 20; Accepted Jul 08 20; Published Jul 3120

\section{Citation}

Please cite this article as follows:

So MC, Aananth R, Suntres EZ. Determination of pharmacokinetic parameters of a four-armed, guanidinium-rich structurally nanoengineered antimicrobial peptide polymer: A research protocol. URNCST Journal. 2020 Jul 31: 4(6).

https://urncst.com/index.php/urncst/article/view/193

DOI Link: https://doi.org/10.26685/urncst.193

\section{Copyright}

(C) Matthew C. So, Rohan Aananth, Emmanuel Z. Suntres. (2020). Published first in the Undergraduate Research in Natural and Clinical Science and Technology (URNCST) Journal. This is an open access article distributed under the terms of the Creative Commons Attribution License (https://creativecommons.org/licenses/by/4.0/), which permits unrestricted use, distribution, and reproduction in any medium, provided the original work, first published in the Undergraduate Research in Natural and Clinical Science and Technology (URNCST) Journal, is properly cited. The complete bibliographic information, a link to the original publication on http://www.urncst.com, as well as this copyright and license information must be included.

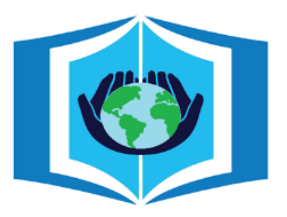

\section{URNCST Journal \\ "Research in Earnest"}

\section{Funded by the Government of Canada}

\section{Canadà̀}

Do you research in earnest? Submit your next undergraduate research article to the URNCST Journal!

| Open Access | Peer-Reviewed | Rapid Turnaround Time | International |

| Broad and Multidisciplinary | Indexed | Innovative | Social Media Promoted |

Pre-submission inquiries? Send us an email at info@ urncst.com | Facebook, Twitter and LinkedIn: @ URNCST

Submit YOUR manuscript today at https://www.urncst.com! 